\title{
The Impact of Behavioural Biases on Stock Volatility: Evidence From Pakistan Stock Exchange
}

\author{
IRFAN ULLAH \\ MS Management Sciences, City Univerity of Science and Information Technology \\ Dalazak Road Peshawar, KP Pakistan \\ DR. MUHAMMAD ZAHID \\ Assistant Professor, City Univerity of Science and Information Technology \\ Dalazak Road Peshawar, KP Pakistan \\ Mianmz11@gmail.com \\ ZAIN ULLAH \\ Lecturer, City Univerity of Science and Information Technology \\ Dalazak Road Peshawar, KP Pakistan \\ Zain.ullah@cusit.edu.pk
}

\begin{abstract}
The main purpose of the current study is to investigate the impact of behavioural biases such as confidence, optimism, and pessimism on stock volatility evidence from Pakistan Stock Exchange (PSX). Prospect theory and overconfidence theory formed the foundation of this study. The methodology composed of positivist philosophical stance, deductive approach and quantitative methods with secondary data. Data analysis involved the use of descriptive statistics, correlation and regression. The study consists ofa 10-years analysis from June 2008 to June 2018 and includes daily trading volumes KSE-100 index in PSX. Results reveal that behavioral biases such as confidence have a positive impact on stock volatility. Similarly, optimism bias has also a positive impact on stock volatility. While pessimism bias has recorded a negative impact on stock volatility. Therefore, it is concluded that behavioural biases have an impact on stock volatility. The current study has a contribution to the body of knowledge on the ground that it attempts to change the traditional notion of society who believes in the efficient market hypothesis. The study has implications for different stakeholders of stock markets.
\end{abstract}

Keywords:Confidence, Optimism, Pessimism, Stock Volatility, Pakistan Stock Exchange

\section{Introduction}

Human beings in their everyday lives of decision making are occasionally biased unintentionally or intentionally (Mahina et al., 2017).Frequently, psychologists observe human behavior and their attitudes to measure the deviation of their decisions from rationality. Adam Smith stated that there is an understanding of the human mindset that is also, in the modern term, known as behavioral finance(Opreanand Tanasescu, 2014). Behavioural Finance is a study of the psychological and emotional states affecting the economic and financial decision making(Kengatharan, 2014). Behavioural finance and economics are related as both attempt to understand the decision-making tendency influenced by the psychology of the person. Reasonably a 
fresh branch of finance, behavioral finance considers values of psychology, sociology, and economics to the area of finance(Opreanand Tanasescu, 2014).Human beings take different decisions in their life according to their environment. Some of them are planned decisions whileothers are unplanned (Prosad, 2014). According to Sinha (2015)investment is a risky decision but most of the individuals make investment decisions without proper analysis and planning for which they feel embarrassed later on.Investment is defined that the present sacrifice of resources and obtaining future benefits (Zuravicky, 2005). Investment by definition looks so simple but in practice, it is a dynamic and difficult process. Investments depend so many factors one is related to the external environment for example firm performance and market performance. While others are related to the psyche of the investors for example confidence, optimism, mentality, and information. Sukanyaand Thimmarayappa (2015) argued that many investment decisions were based on an Efficient Market Hypothesis (EMH). The EMH was initially presented in 1970 by the Eugene Fama. The model or ideas of rational investors' behaviuor as well as market efficiency, who believes that stockholders will create a good and clever decision. In 1970, Fama demonstrated the achievement of prestigious market efficiency "EMH".According to the EMH "in an efficient market securities prices reflect all available information and there is no chance for above or below average returns" (Fama, 1970).

If the Fama (1970) is right in his notion all the participants of the market must have almost the same returns regardless of whatever strategy they follow. But in real-time there are countless examples where the participants of the same market have different returns, thus, the author assumes that this variation in returns of the individual investors is due to the behavioral biases that lead to such different returns (Oprean and Tanasescu, 2014). Thus, on the basis of the above arguments, the researcher found a research gap to investigate those biases which have a different effect on different investors' perceived trading return. Hence, there is a dearth of research to investigate such situations in the Pakistani context (Naveed, 2015). The current study has contributed to the body of existing knowledge on the ground that it attempts to change the traditional notion of society who believes in the efficient market hypothesis. Market efficiency hypothesis can be challenged in Pakistan in light of the results obtained. The study also highlighting the psychological factors that affect the thought process of the investors and lead them to make irrational decisions. The current research also investigates theeffects induced by temperament on investment behavior, influencing trading volume.Elements such as investor confidence, optimism, and pessimism are taken into account to explain the link between investor behavior and trading volume.

\subsection{Research Questions:}

- Does confidence impact stock volatility in the KSE-100 index?

- Does optimism impact stock volatility in the KSE-100 index?

- Does pessimism affect stock volatility in the KSE-100 index?

\subsection{Objectives of the Study}

The main objectives of the research areas;

- To investigate the impact of confidence on stock volatility in the KSE-100 index.

- To investigate the impact of optimism on stock volatility in the KSE-100 index. 
- To examine, the impact of pessimism on stock volatility in the KSE-100 index.

\section{Literature Review}

This section provides the main theories on which the current research idea has been based. Moreover, empirical research has been provided in support of research questions. Finally on the basis of following theories and literature review hypothesis for testing has been developed.Before going to discuss behavioral biases i.e. Confidence, Optimism, and Pessimism and how individual make a decision and minimize these biases. Every individual constantly makes a decision involving a different level of risk and uncertainty. Because decisions have such a large effect on how we behave. A number of different theories are developed by different psychologist and economist, which explain how individual behave while taking investment decisions, some of them which support the current research are explained below.

\subsection{Efficient Market Hypothesis (EMH)}

An efficient market hypothesis was developed in 1970 by "Fama", which claims that security values reveal all available information (for example, information to the public, non-public information, and history of information). Fama (1970) in his essay on the interpretation of theories and the creation of growing experimental evidence. $\mathrm{He}$ pointed to the theory of market efficiency, pointing out that investors are confident that current stock prices are completely removed from existing securityrelated information and based on that return. This perspective is in line with their risk. The inefficient capital market value quickly correlates with new or updated data, and current stock prices fully reflect existing data known as the "Efficient Information Market". Fama (1970) divides the actual results into these articles into three sets.First is weak-form EMH, second semi-strong form EMH and last is strong form EMH. Weak form EMHexplains that the existing market value effectively reflects all the information on the stock market with previous data and market data.Semi strong form EMHexplains that stock prices show all available public data, all past and current information e.g., dividends on shares, price-earnings ratio, accountinginformation, and new product development. While Strong form market hypothesis explain that stock prices demonstrate all publicallyavailable data and private information.

\subsection{Prospect Theory}

Prospect theory was proposed by two famous scientists from the United States, Kahneman, and Tversky around 80s. According to prospect theory, people give different values to losses and gains, their attitudes towards losses and gains have different. Furthermore, these decisions have based on prior gains and prior losses rather the state of their wealth.He also states that information regardinginvestment could change the perception or behaviour of the investor.The proposed principles include the principle of the function value, decision frame, psychological accounting, probability, and the effect of certainty.There are some researchers who consider this theory as the base for the understanding of behavioral finance.

\subsection{Behavioural Biases}

Pompian (2012) notes that in the financial also economic scope, behavioural biases refers to the propensity of decision-making that leads to unreasonable financial decisions affected by misconceptions as well as emotional reasons. Behavioral biases will certainly play an important role wherever human beings are involved and 
whenever they deal in a financial transaction for making practical decisions. They must not only have sufficient information but they must know their-selves too in order to make their decision right (Prosad, 2014). Investors are not free of biases. This can be found from their study and they clearly said too that an appropriate and adequate knowledge can reduce the risks of irrational behavior. Behavioral biases mean the use of psychology and sociology in the field of finance. In simple words deviation from the rational decision. In recent time it seems that investors are not rational. It means that in stock exchange investors' decision are not rational. Consequently, most investment decisions in stock exchange were affected by behavioural biasesand emotions i.e. Confidence, Optimism and Pessimism biases (Mahinaet al.., 2017 and Brabazon, 2000). In literature, a number of behavioural biases exist but this study will contain only three independent variables (biases) i.e. Confidence, Optimism and Pessimism biases. Which are explained below?

Psychologist Frank (2003) found that investors face many biases during investment decision but one of the foremost common bias is confidence bias.Barber and Odean (2001) explained in his study that if the investor is confidence, they can do more and more investment. Consequently, confident investors are the risk taker and thus the level of their investment increase more than others and due to this trading volume is increasedAdel and Mariem(2013). Subash (2012) also found that confident traders rely too much on their own data and also appropriately judge the accuracy of this data. Barber and Odeon's (2001) stated that confident traders also perform rational transaction due to which they receive a high return. In addition, they also accept higher risk. It means that confident investors are the high-risk taker and which reward then in high returns.Meier (2016) used Egyptian Stock markets data and explain a positive impact of confidence bias on trading activities. They also state trading volume increases with investor's confidence. In Pakistan, stock market confidence bias has also some good and bad impact. Scholar explains that Pakistani investors' confidence continuously keeps in mind the outcomes that they will acquire from the stock market. They continuously need to extend their revenue due to this, they do alarge transaction in markets (Tariq \& Ullah, 2013). According to Gervais and Odean (2001) past success or positive outcome encourages investors' confidence.Statman et al., (2012) stated that due to confidence bias some other biases also arise like optimism bias and pessimism bias.

Optimism bias firstly describes by Irwin in 1953. The tendency of people to be unrealistically optimistic about lifeevents (Weinstein 1980). Further described by different authors in recent years like Irwin (1953) and Weinstein (1980)Slovic,Fischoff and Lichtenstein (1982) andSlovic(2000).Previous literature support that optimistic investors are overvaluing future outcomes According toPuri and Robinson (2007) that many optimistic investors overestimate their future outcomes but they undervalue unfavorable events. Due to this overestimation, optimistic investors increase their investment level and that's why the trading volume is increased. Another author explains that some time optimistic investors take a substantial risk and due to that risk they increase investment volume (Dhaoui, 2012). It means that optimism bias significantly motivates the risk-taking behavior of the investors. As a result of this risk-taking behavior optimistic investors' not only trade more but also increase the level of their investment volume in risky assets (Kahneman \&Lovallo, 1993; Palme, Sunden\&Soderlind, 2005). However, their decision is also based on market condition if market conditions change their decision is also change 
(Puri and Robinson, 2007).Another author also relates that optimistic investor is like a confident investor and both are willing to make risky transactions and both make irrational investments as a result, abnormal volatility arises (Oprean \& Tanasescu, 2014). In the last few years many previous studies such as Akerlof, 2009; Haruvy et al., 1999; Guldberg and Shiller, 2010 and Barberis et al., (2008) highlighted only psychological factors which impact on financial markets and stock volatility. The authors also explain that all investors are not rational and their claim for risky stocks depends on their emotional factors i.e. confidence, optimism, and pessimism. Most of the investment process was affected by behavioral biases and emotional factors. Behavioral biases play a key role in investments decisions. One of them is behavioral bias which shows a dynamic role in the investment process and its impact on stock volatility. That is investors' pessimism. Pessimism bias defines that investors undervalue the mean and overvalue the fluctuations of the outcomes of the risky stocks (Brabazon, 2000). Germain and Rousseau (2006)found in the French stock market that pessimist investors' will not trade or decrease their trading level to avoid risk and losses. The authors also state that pessimistinvestors are more risk aversed and due to this, they reduce their trading volume. In the French stock market, pessimism bias has a negative impact on trading volume. Shu (2010) also states that pessimist investors' show a high level of risk aversion. So through this, they decrease their trading volume.

\subsection{Hypothesesof Research Study}

On the basis of the above literature review discussed in this chapter, the following hypotheses are established

$\mathrm{H}_{1}$. Confidence has a positive impact on stock volatility.

$\mathrm{H}_{2}$. Optimism has a positive impact on stock volatility.

$\mathrm{H}_{3}$. Pessimism has a negative impact on stock volatility.

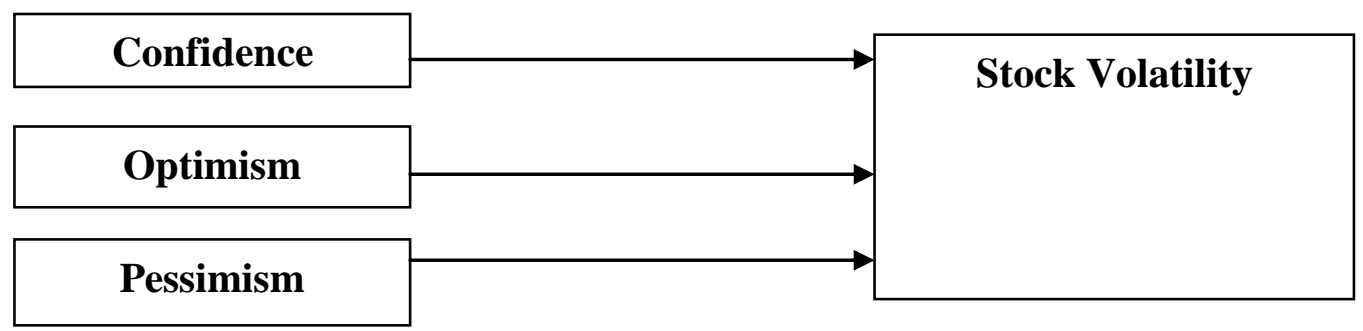

Fig: 1 Conceptual Framework

\section{Research Methodology}

The current section gives detailed information about the research methodology. And also talking about how the scholar has carried out or completed the current study. In a current research study, a positivist approach is used, because this approach believes in a single fact and can be measurable and identified, normally relates to quantitative methods. It usually generates a hypothesis which can be tested (Guba and Lincoln, 1994).According to Saunders et al. (2009), the larger size of the sample signifies the character of the entire population, but the size of the sample which well selected for the research study normally depends upon time, financial position and resources of the scholar (Flick, 2011). In quantitative research, the size of the sample is essential in determining the reliability of the results of a study(Bryman, 2012). Therefore, this 
study is based on secondary data. The sample consists of KSE-100 index and Daily Stock Market data will be for 10 years that is from $1^{\text {st }}$ June 2008 to $31^{\text {st }}$ June 2018. Thus, it stretches over a long period of time as well as it is up to date, which makes it somewhat consistent with the data for behavioral biases, which are good for the reliability of the dataset (Sniederand Larner, 2009).Following are the measures used for the variables in the current study.

For independent variable i.e. Confidence. The study used the following two models given below.

$$
\left\{\begin{array}{l}
\text { if }: R_{t-1} \geq 0 \rightarrow \text { there }{ }_{-} \text {will_be_transactions } \\
\text { if }: R_{t-1}<0 \rightarrow \text { there } e_{-} \text {will_be_no_transactions }
\end{array}\right\}
$$

Where $\mathrm{R}(\mathrm{t}-1)$ shows previous date returns. If the previous date returns are greater or equal to zero so, in this situation confidence is occurs. But if the previous date returns are less than zero this situation no-confidence shown by investors. This measure was used inUlussever, Guranyumusak and Kar (2011) and Dhaoui et al. (2012)Oprean and Tanasescu(2014).

For independent variable i.e. Optimism. The study used the following two models given below.

$$
\left\{\begin{array}{l}
\text { if }: R_{t-1} \geq \bar{R}+\sigma \rightarrow \text { there_will_be_transactions } \\
\text { if }: R_{t-1}<\bar{R}+\sigma \rightarrow \text { there_will_be_no_transactions }
\end{array}\right\}
$$

Where $\mathrm{R}(\mathrm{t}-1)$ shows previous date returns. $\hat{\mathrm{R}}$ show average return. $\sigma$ show standard deviation.Optimistic investors will trademorewhen the previous return of the previous period is greater than or equal to, the average return of the entire period.But if the previous date returns are less than average return, so they will postpone the trading. This measure was used in Dhaoui (2011) and Oprean and Tanasescu (2014).

For independent variable i.e. Pessimism. The study used the following two models given below.

$$
\left\{\begin{array}{l}
\text { if }: R_{t-1} \geq \bar{R}-\sigma \rightarrow \text { there_will_be_transactions } \\
\text { if }: R_{t-1}<\bar{R}-\sigma \rightarrow \text { there_will_be_no_transactions }
\end{array}\right\}
$$

Where $\mathrm{R}(\mathrm{t}-1)$ shows previous date returns. $\hat{\mathrm{R}}$ show average return. $\sigma$ show standard deviation. Pessimistic investors will not investif the loss is the preceding period is increase than the worth; else, if the loss is less, they will endure trading.This measure was used in Dhaoui (2011)and Oprean and Tanasescu (2014).

Statistical Package for Social Science (SPSS v.20) was used for the estimation of collected data. The study applied different statistical estimations like, descriptive statistics are used to describe the mean minimum, maximum, and standard deviation of the data. Correlation matrix which analysis and shows us how to decide together the nature and magnitude of the association between two variables. The last one ismultiple regression describes the degree of dependence of one variable on the others. In this regard, the following is the regression model developed by the current study.

$\mathrm{S} . \mathrm{V}=\alpha+\beta 1 \mathrm{CONF}+\beta 2 \mathrm{OPTM}+\beta 3 \mathrm{PSM}+\mathrm{e}$ 
Where by the variables will be identified as following.

S.V is Dependent Variable represent Stock Volatility

CONF is Confidence

OPTM is Optimism

PSM is Pessimism

ais Constant

$\mathrm{e}$ is an error term

Here it is mentioned that the coefficient $\beta$ in the above-given equation shows the direction and strength of the relationship between independent variables i.e. (Confidence, Optimism, and Pessimism) and dependent variables (Stock Volatility).

\section{Estimation And Empirical Analysis}

This part of the study will analyze the results. The author will use descriptive statistics to summarize and describe the data in section 4.1 , followed by the correlation matrix to show whether and how strongly pairs of variables are related in section 4.2. Finally section 4.3 the regression has been estimated.

Following are descriptive statistics to investigate the performance of all variables in current research.

Table 1: Descriptive Statistics

\begin{tabular}{lccccc}
\hline & $\mathbf{N}$ & Min & Max & Mean & Std. Dev \\
\hline Stock Volatility & 2039 & 8.99 & 17.80 & 11.49 & 0.617 \\
Confidence & 2039 & 0 & 1 & 0.58 & 0.493 \\
Optimism & 2039 & 0 & 1 & 0.60 & 0.490 \\
Pessimism & 2039 & 0 & 1 & 0.59 & 0.492 \\
\hline
\end{tabular}

Table 1 shows that there are 2039 observations used for the current study. The stock volatility that is computed by the log of trading volumehas a minimum value of 8.99 , the maximum value of 17.80 and a mean of 11.49 with a standard deviation of 0.617 . Confidence is calculated through dummy scale of $(0$ and 1) where 0 represents No transaction and 1 represent Yes transaction and varies from minimum 0 to maximum 1 with a mean of 0.58 and a standard deviation of 0.493 showing that it is a standard normal distribution. Similarly, the statistical findings for optimism have a minimum of 0 to a maximum of 1 because on a dummy scale of $(0$ and 1$)$ where 0 represents No transaction and 1 represent Yes transaction. It has a mean of 0.60 with a standard deviation of 0.490 . Finally, pessimism variable has a minimum of 0 to a maximum of 1 and a mean of 0.59 with a standard deviation of 0.492 .

Table 2: Pearson's Correlations Matrix

\begin{tabular}{lcccc}
\hline & $\begin{array}{c}\text { Stock } \\
\text { Volatility }\end{array}$ & Confidence & Optimism & Pessimism \\
\hline Stock Volatility & 1 & & & \\
Confidence & $0.655^{* *}$ & 1 & & \\
Optimism & $0.651^{* *}$ & $0.723^{* *}$ & 1
\end{tabular}




$\begin{array}{lllll}\text { Pessimism } & 0.008 & -0.016 & -0.017 & 1\end{array}$

**. Correlation is significant at the 0.01 level (2-tailed).

In statistics, the Pearson's correlation coefficient is used to measure the relationship between two quantitative random variables. In other word, it can also be defined as the index which is used to measure the level of association among two variables as long as both variables are quantitative. The correlation coefficient value lies in between -1 and +1 where the negative and positive signs indicate us the direction of the relationship. From the above-given correlation matrix table, 4.2 shows a clear result for the variables under the study that is stock volatility, confidence, optimism, and pessimism. The above empirical results show that there is a hundred percent correlation of every explanatory variable with itself; however, each has a different level of correlation with other variables.It is evident that there is a statistically significant positive association of confidence with stock volatility at a correlation coefficient of 0.655 at $\alpha<0.01$. Similarly, optimism is also found to be significantly and positively correlated with stock volatility at a correlation of 0.651 at $\alpha<0.01$. Finally, pessimism positively correlated but insignificantly at a correlation coefficient of 0.008 at $\alpha>0.01$. In short, all the variables have a positive association with that of the dependent variable "stock volatility" however some of them have significant and positively strong correlation while othershavea weak insignificant and negative correlation.

Table 3: Regression Analysis Results

Unstandardized Collinearity Statistics Coefficients

\begin{tabular}{|c|c|c|c|c|c|c|}
\hline & $\mathbf{B}$ & Std. Error & $\mathbf{t}$ & Sig. & Tolerance & VIF \\
\hline (Constant) & 0.175 & 0.013 & 13.434 & 0.000 & & \\
\hline Confidence & 0.370 & 0.043 & 8.603 & 0.000 & 0.149 & 6.732 \\
\hline Optimism & 0.313 & 0.043 & 7.245 & 0.000 & 0.149 & 6.732 \\
\hline Pessimism & 0.295 & 0.000 & 1.160 & 0.246 & 1.000 & 1.000 \\
\hline $\begin{array}{c}\text { R-squared } \\
\text { Watson2.050 } \\
\text { Adjusted R }{ }^{2}\end{array}$ & 0.444 & \multicolumn{3}{|c|}{ statistic 541.940} & \multicolumn{2}{|c|}{ DW/Durban } \\
\hline
\end{tabular}

a. Dependent Variable: Stock Volatility

The empirical results of the current study show thatR-squared, 44.4percent of changes that may occur in the dependent variable,stock volatility,is explained by independent variables. Furthermore, the F-statistic of 541.940 with the significance of 0.000 shows that the model as a whole is statistically significant and reliable at $\alpha<0.05$. Finally, the Durban Watson (DW) statistics of 2.050depicts that there is no problem withautocorrelation.It is standard that any DW value below 1.00 or above 3.00 indicates a serious issue of autocorrelation (Gujarati, 1995and Wooldridge, 2002).The results show that confidence and optimism has a positive impact on stock volatility. While pessimism is found to negatively impact on stock volatility. The value of the constant shows that if all the independent variables become zero, still 
0.175 variation will be recorded independent variable. Confidence has a significantly positive impact of 0.370 with a significance level of 0.000 or $\alpha<0.05$ on stock volatility. Optimismis, expectedly, found to have a positive impact of 0.313 with a significance of 0.000 or $\alpha<0.05$ on stock volatility.Finally, pessimism is found to have an insignificantly positive impact on stock volatility with a coefficient of 0.295 with the significance of 0.246 or $\alpha>0$.1.Further, co-linearity statistics i.e. tolerance and Variance Inflation Factors (VIF) result makes it clear that there is no multicollinearity problem as the VIF value of all the variables are in between 1-10 (Ringle et al.., 2015; Hair et al.., 1995). Thus, considers all the above analysis valid and free of co-linearity problem.

\section{Conclusion}

Current research is an attempt to study the influence of behavioural biases i.e. confidence, optimism and pessimism on stock volatility. In this respect, the purpose of the study, research questions, and hypotheses were designed on the basis of literature review. The data are collected and analyzed, the results obtained and the recommendations made accordingly. The current section provides a detailed discussion of the objectives achieved, the answers to research questions and the acceptance and rejection of hypotheses.This study was designed to find the behavioural biases and its impact on stock volatility. For this purpose, three independent behavioral biases were selected i.e. confidence, optimism, and pessimism, while stock volatility was selected as a dependent variable. And secondary data has been collected from different reliable sources and statistical tools Pearson correlation used to check the association among the variables and multiple regression are used to check the impact level and variation caused by independent variables in the dependent variable. Average values of confidence, optimism, and pessimism are $0.58,0.60$ and 0.59 and the $T$ values 8.603, 7.243 and 1.160 respectively, which confirms that these variables have a strong and significant impact on stock volatility. Results of the study conclude that confidence and optimism has a positive impact on stock volatility but pessimism has a negative impact on stock volatility. To conclude, this study establishedthree hypotheses (H1 to H3) for investigating the impact ofbehavioural biases on stock volatility. The study empirically examined these hypotheses in the context ofthe Pakistan Stock Exchange. The study found that all hypotheses are accepted.

According to prospect theory which can be explained in the literature review, peoples give different values to losses and gains, their attitudes towards losses and gains different. Hence, if two equal choices given to a person, the first one choice expressed possible to gain and the second choice expressed possible losses, consequently individuals would always select the first one choice (Kahneman and Tversky, 1979). Accordingly, prospect theory if investors receive profits then they increase their trading volumes like optimist and confident investors. But if they receive losses then they reduce trading like pessimist investors.

\section{References}

Adel, B., \& Mariem, T. (2013). The Impact of Overconfidence on Investors' Decisions. Business and EconomicResearch, 6(2), 2013,199-225.

Bryman, A. (2012). Social research methods (5 ${ }^{\text {th }}$ ed.). Oxford: Oxford University Press, New York, 2012.

Barberis, N., Shleifer, A. \& Vishny, R. (2008). A model of Investor Sentiment. 
Journal of Financial Economics, 49, June 1998, 307-343.

Dhaoui, A. (2012). Animal Spirits and Volatility of the Trading Volume in International Financial Markets between 2002 and 2011. Papers.Ssrn.Com, I (1), 163-183.

Flick, U. (2011). Introducing research methodology: A beginner's guide to doing a research project. London: Sage.

Fama, E. (1970).Efficient Capital Markets: A Review of Theory and Empirical Work. Journal of Finance. 25 (2): 383-417.

Germain, L., Rousseau, F. \& Vanhems, A. (2006). Optimistic and Pessimistic Trading in Financial Markets, 1-28.

Gervais, S. \& Odean, T. (2001). Learning to be Overconfident. Review of Financial Studies, vol. 14, pp. 1-27.

Gujarati, D. (1995), Basic Econometrics, McGraw-Hill, Singapore.

Hair, J. F. Jr., Anderson, R. E., Tatham, R. L. \& Black, W. C. (1995). Multivariate Data Analysis (3rd ed). New York: Macmillan.

Kengatharan, L. (2014). The Influence of Behavioral Factors in Making Investment Decisions and Performance: Study on Investors of Colombo Stock Exchange, Sri Lanka. Asian Journal of Finance \& Accounting, 6(1), 1-23.

Mahina, J., Muturi, W. \& Florence. (2017). Effect of Behavioural Biases on Investments at the Rwanda Stock Exchange. International Journal of Accounting, Finance and Risk Management, 2(4), 2017, 131-137.

Meier, C. (2016). Aggregate investor confidence in the stock market, (February 2016).

Iqbal, N. (2015). Impact of Optimism Bias on Investment Decision: Evidence from Islamabad Stock Exchange, Pakistan. Research Journal of Finance and Accounting, 6(19), 2015.

Oprean, C. \& Tanasescu, C. (2014). Effects of Behavioural Finance on Emerging Capital Markets. Procedia Economics and Finance, 15(14), 2014, 1710-1716. https://doi.org/10.1016/S2212-5671(14)00645-5.

Prosad, M. J. (2014). Impact of Investors' Behavioral Biases on the Indian Equity Market and Implications on Stock Selection Decisions: An Empirical Analysis. Jaypee institute of information technology. India.

Pompian, M. (2012). Behavioural Finance and Investor Types: Managing Behaviour to Make Better Investment Decisions. New York: John Wiley \& Sons.

Puri, M., \& Robinson, D. T. (2007). Optimism and Economic Choice. Journal ofFinancial 27Economics, 86 (1), 2007, 71-99.

Palme, M., Sunden, A. \& Soderlind, P. (2005). Investment Choice in the Swedish Premium Pension Plan. Working Papers.

Sukanya, R. \& Thimmarayappa, R. (2015). Impact of Behavioural biases in Portfolio investment decision making process. International Journal of Commerce, Business and Management (IJCBM), 4(4), 2015, 1278-1289.

Sinha, P. C. (2015). Stocks' pricing dynamics and behavioral finance: A review. Growing Science, 5, 2015, 797-820.

Statman, M., Thorley, S., \& Vorkink, K. (2012). Investor Overconfidence and Trading Volume Investor Overconfidence and Trading Volume, 19(4), 2012, 15311565.

Subash, R. (2012). Role of Behavioral Finance in Portfolio Investment Decisions: Evidence from India. (Social Sciences), Charles University in Prague, Prague. 
Shu, H. C. (2010). Investor mood and financial markets. Journal of Economic Behavior and Organization, 76(2), 2010, 267-282. https://doi.org/10.1016/j.jebo.2010.06.004

Snieder R. \& Larner, K. (2009). The Art of Being a Scientist: A Guide for Graduate Students and their Mentors, Cambridge: Cambridge University Press.

Saunders, M., Lewis, P. \& Thornhill, A. (2007). Research Methods for Business Students, $\left(6^{\text {th }}\right.$ ed. $)$ London: Pearson.

Wooldridge, J.M. (2002). Econometric Analysis of Cross Section and Panel Data, The MIT Press, Cambridge, MA, and London.

Zuravicky, O. (2005).The Stock Market: Understanding and applying ratios, decimals,fractions, and percentages, The Rosen Publishing Group, Inc. 